\title{
REPRESENTAÇÕES DISCURSIVAS SOBRE A ESCRITA ACADÊMICA E SEU ENSINO NO CONTEXTO DO ISF
}

\author{
REPRESENTACIONES DISCURSIVAS SOBRE LA ESCRITURA ACADÉMICA Y SU \\ ENSEÑANZA EN EL CONTEXTO DEL PROGRAMA IDIOMAS SIN FRONTERAS - ISF
}

DISCURSIVE REPRESENTATIONS OF ACADEMIC WRITING AND ITS TEACHING IN THE CONTEXT OF THE LANGUAGE WITHOUT BORDERS PROGRAM

RESUMO: Este trabalho visa analisar algumas representações discursivas de escrita acadêmica e de seu ensino, construídas por professores que atuaram no Programa Idiomas sem Fronteiras. Com base nos estudos da Linguística Aplicada, em teorias do letramento e do discurso, investigamos postagens feitas em um fórum de discussão, no Moodle, no qual os participantes se posicionaram acerca de suas experiências com a escrita acadêmica como aprendizes e professores. A partir da análise das regularidades enunciativas, presentes nos dizeres dos professores, observamos a representação da escrita como prática incomum e exigente e seu ensino como enfadonho. As análises acenam para a constituição de uma memória discursiva que (des)vela a tensa relação do professor brasileiro de língua inglesa com a escrita acadêmica.

PALAVRAS-CHAVE: Escrita acadêmica. Formação de professores. Língua inglesa.

RESUMEN: Este artículo tiene como objetivo analizar algunas representaciones discursivas de la escritura académica y su enseñanza, construidas por profesores que trabajaron en el Programa Idiomas sin Fronteras. Con base en los estudios de Lingüística Aplicada, en teorías de la literacidad y teorías del discurso, investigamos las publicaciones realizadas en un foro de discusión de

\footnotetext{
* Professora Associada na Universidade Federal de Uberlândia. Doutora em Linguística Aplicada pela Universidade Estadual de Campinas (Unicamp). Líder do Grupo de Pesquisa 'Laboratório de Estudos Polifônicos'. E-mail: depaulabrito@gmail.com
} 
Moodle, en el que los participantes se posicionaron sobre sus experiencias con la escritura académica como estudiantes y profesores. A partir del análisis de las regularidades enunciativas, presentes en los relatos de los docentes, observamos la representación de la escritura como una práctica inusual y exigente y su enseñanza como aburrida. Los análisis apuntan a la constitución de una memoria discursiva que (re)vela la tensa relación entre el profesor brasileño de lengua inglesa con la escritura académica.

PALABRAS CLAVE: Escritura académica. Formación de profesores. Lengua Inglesa.

ABSTRACT: This work aims to analyse some representations of academic writing and its teaching built by teachers that participated in the Language without Borders Program. Based on the studies of Applied Linguistics, in the theories of literacy and of discourse, we investigate posts from a discussion forum on Moodle, in which participants took a stance on their experiences concerning academic writing both as teachers and as learners. From the analysis of the enunciative regularities, present in the posts of the teachers, we observe the representation of writing as uncommon and demanding and its teaching as boring. The analyses point to the constitution of a discursive memory that (un)veils the tense relation of the Brazilian English teacher with academic writing.

KEYWORDS: Academic writing. Teacher education. English Language.

\section{INTRODUÇÃO}

Pensar a escrita como instância de formação docente significa recusar visões que a tomam como mera habilidade técnica e neutra para concebê-la como prática discursiva em que os sujeitos se inscrevem para (se)significar. Escrita, nesse sentido, é sempre escrit(ur)a, já que não se escreve sem se estar implicado, sem tomar um posicionamento diante das vozes sócio-históricas que constituem os enunciados. Sendo a palavra o "fenômeno ideológico por excelência" (BAKHTIN/VOLOCHINOV, 2020 [1929], p. 41, grifos do autor), compreendemos que a escrita - como ato de tomada da palavra - demanda sempre uma assinatura por parte do sujeito (BAKHTIN, 2010 [1920]).

Vários estudos têm se dedicado a pensar o lugar da escrita no desenvolvimento profissional de professores de línguas (AUGUSTINI; BERTOLDO, 2017; OLIVEIRA; ARAÚJO, 2017; JUCHUM, 2014; FIAD, 2011; MARINHO, 2010). Trata-se, pois, de compreender, como pela/na escrita, podem-se entrever possibilidades de deslocamentos subjetivos e ressignificações teórico-metodológicas, que, por sua vez, contribuem para a constituição de um espaço de enunciabilidade que sustente a posição de professor.

Neste trabalho, propomos uma reflexão sobre a escrita, no contexto das práticas pedagógicas desenvolvidas por professores bolsistas no Programa Idiomas sem Fronteiras (IsF), no qual atuamos como coordenadora pedagógica na língua inglesa. O IsF, criado em 2012, restringia-se de início apenas ao ensino da língua inglesa, daí ser intitulado Inglês sem Fronteiras. Em 2014, o programa passa a abranger outras línguas e adquire o nome de Idiomas sem Fronteiras. Seu propósito original era atuar na capacitação linguística de estudantes de nível superior, funcionando, assim, como apoio ao Ciência sem Fronteiras. Hoje, o programa atua na consolidação de uma política linguística visando à internacionalização do Ensino Superior Brasileiro e oferece residência docente para os futuros profissionais do ensino de línguas estrangeiras, exercendo importante papel na formação do professor (SARMENTO; ABREU-ELIMA; MORAES FILHO, 2016), sobretudo ao atuar em uma área pouco trabalhada nos cursos de licenciatura em Letras, a saber: 0 ensino de línguas para fins específicos (CRISTÓVÃO; BEATO-CAETANO, 2016).

Dentre os vários cursos ministrados pelos professores para a comunidade universitária, no âmbito do IsF, encontram-se cursos focados na produção escrita de abstracts, cartas de apresentação, currículo, essays e e-mails ${ }^{1}$. O ensino da escrita para fins acadêmicos ocupa, pois, espaço de destaque dentro do programa, mesmo nos cursos com foco na produção ou compreensão oral ${ }^{2}$, haja vista a estreita relação escrita-oralidade no contexto acadêmico.

\footnotetext{
${ }^{1}$ Os cursos têm duração de 16, 32,48 ou 64 horas e abrangem os níveis A2 a C1, conforme o Quadro Comum Europeu de Referências para Línguas (QCER).

${ }^{2}$ Tais como os cursos de "Compreensão oral: palestras e aula", "Produção oral: debates", "Produção oral: interações acadêmicas", "Produção oral: comunicações acadêmicas”, dentre outros.
} 
Nosso objetivo é compreender a relação que os sujeitos estabelecem com a escrita, entrevendo as formações imaginárias (PÊCHEUX, 1997 [1969]) que vêm à baila ao enunciarem sobre a escrita acadêmica e seu ensino. O professor escreve - e fala sobre a escrita - a partir de imagens que constrói acerca de si e do outro, delineando, assim, representações que são sócio-histórica e ideologicamente constituídas e postas em funcionamento nos processos discursivos. Desse modo, interessa-nos analisar algumas representações de escrita acadêmica e de seu ensino, construídas por professores que atuaram no IsF, de forma a identificar os atravessamentos discursivos que perpassam essas representações.

Entendemos que a relação do professor em formação com a escrita acadêmica (em língua materna e/ou estrangeira) incide em sua prática pedagógica, daí a importância de se problematizá-la. Não se trata de postular uma relação transparente ou de mera transposição entre as representações que o sujeito constrói e as práticas pedagógicas que propõe, haja vista serem diferentes instâncias de tomada da palavra. Ademais, sendo a linguagem - e o sujeito - perpassada pela contradição, pela polifonia, pela falta e pela heterogeneidade, a coincidência do dizer consigo mesmo só existe enquanto ilusão (PÊCHEUX, 1997 [1975]). Dessa forma, investigar as representações construídas acerca da escrita acadêmica nos parece importante na medida em que pode nos permitir problematizar concepções e memórias naturalizadas, que sedimentam práticas teóricas, metodológicas e pedagógicas, e possibilitar deslocamentos subjetivos.

Para refletir sobre a relação desses sujeitos com a escrita, fundamentamo-nos nos estudos da Linguística Aplicada, em teorias do letramento e do discurso, em especial, nos trabalhos de Pêcheux e do Círculo de Bakhtin, que, apesar de suas especificidades, convergem no sentido de nos permitirem pensar a linguagem como prática social, histórica e ideologicamente situada. Entendemos que tais abordagens teóricas contribuem para a problematização dos sentidos naturalizados, que produzem efeitos de verdade e engendram relações de poder-saber, as quais incidem nos processos de ensino-aprendizagem de línguas e de formação docente. Assim, a interlocução teórica que aqui aventamos acena para a possibilidade de se conceber esses processos sem a pretensão de uma visão totalizante que, recusando a falha, o equívoco, a contradição, investe na busca de uma ilusória completude.

Em termos de organização, além dessa introdução e das considerações finais, discutimos a relação da escrita com a formação do professor de línguas; e em seguida, passamos à descrição, análise e discussão das representações discursivas acerca da escrita acadêmica e seu ensino-aprendizagem.

\section{A ESCRIT(UR)A E A FORMAÇÃO DO PROFESSOR DE LÍNGUAS}

No bojo dos estudos da Linguística Aplicada, encontram-se discussões sobre a formação do professor de línguas. Tal processo pode ser investigado sob perspectivas e ângulos muito distintos, destacando-se, por exemplo, a organização curricular das licenciaturas; a relação teoria-prática; a proficiência linguística do professor; as questões identitárias; para mencionar alguns. Para o escopo desse trabalho, interessa-nos pensar a formação pela via da escrita acadêmica, tomada como prática social que pode potencializar a constituição subjetivo-discursiva do professor, haja vista que

[...] ler e escrever, no espaço discursivo-acadêmico, implica posicionar-se a partir de um lugar teórico com o qual se identifica. Isso é altamente complexo porque está em jogo perceber que esse engajamento em modos de dizer diferentes exige distinguir, necessariamente, as teorias umas das outras. Trata-se, a nosso ver, de uma oportunidade que os alunos têm de experimentar que as diversas teorias sobre o ensino e a aprendizagem de línguas não constituem o objeto de estudo da mesma forma. Eis aí a complexidade do processo que precisa ser vivido/experimentado. (BERTOLDO, 2017, p. 114)

Riolfi (2011, p. 11), com base na articulação entre os estudos da linguística, da educação e da psicanálise, defende a formação do professor como operação que o auxilie a "a) incluir o outro no cálculo que faz para falar ou para escrever, b) conquistar a sua singularidade e fazer passá-la no mundo; e c) encontrar uma posição enunciativa passível de ser sustentada durante falas públicas”. Na visão da autora, a escrita pode possibilitar transformações na relação do sujeito com o saber, todavia, para isso, é preciso que se 
passe de uma simples "escrita cosmética" (que, sendo inócua, é incapaz de promover mudanças) para uma escrita que "[...] exerce efeitos de interrogação sobre aquele que se propôs a escrever, o ultrapasse” (RIOLFI, 2011, p. 28).

As considerações de Riolfi (2011) sobre a importância da escrita na formação do professor parecem ir ao encontro das discussões de Fairchild (2017) quanto aos problemas de escrita nos relatórios de estágio de licenciandos. Ao apontar que estes fazem uso de descrições vagas, sem caráter investigativo, o autor defende que:

[...] essa forma de escrever não resulta do acúmulo das fragilidades individuais dos estagiários, mas responde ao papel designado pela universidade ao professor. Ela integra um projeto de formação no qual está previsto que o ato de escrever não seja, para o docente, instrumento de trabalho intelectual, mas meio para que ele seja avaliado pelas instâncias que reivindicam o controle de sua atividade laboral - dentre elas, o Estado e, sem dúvida nenhuma, a própria Universidade. É claro que a transferência do controle da atividade de ensino do professor para outras instâncias está condicionada à diminuição da autonomia do próprio professor e, sob esse prisma, à precarização de sua formação teórica, bem como seu confinamento a gêneros escritos que o situam em um foro pessoal em vez de o direcionarem para o diálogo com os pares e com outras comunidades profissionais, exercem um papel importante. (FAIRCHILD, 2017, p. 270)

Sendo mero instrumento de avaliação - e não de trabalho intelectual -, como bem pontua Fairchild, a escrita perde seu potencial de formação e adquire status de 'tarefa escolar' (BRITO, 2012), meio pelo qual se presta conta ao outro (geralmente, ao professoravaliador). Todavia, como salienta Grigoleto (2011, p. 93), “[...] o fazer acadêmico se pauta pela ancoragem no saber já constituído e as escolhas por campos teóricos, objetos de estudo e orientações metodológicas resultam dos recursos específicos feitos nesse saber". Assim, a escrita acadêmica envolve, sobretudo, a relação com as palavras do(s) outro(s); e, mais especificamente, a capacidade de orquestrar diferentes vozes, ao mesmo tempo em que se constrói para si um lugar de singularidade e autoria. Nessa perspectiva, escreve-se para abrir um espaço de interlocução, de produção, de resistência - e não de mera reprodução de conhecimentos estáticos.

Nossa experiência como coordenadora pedagógica no IsF nos traz algumas inquietações advindas tanto das discussões teóricopedagógicas com os professores bolsistas acerca do ensino-aprendizagem de LI para fins acadêmicos, bem como da supervisão da preparação de aulas e materiais didáticos e da observação de aulas, propriamente ditas. No caso específico do ensino da escrita acadêmica, temos levantado alguns questionamentos, a saber: que relação desses sujeitos com a escrita é possível entrever a partir dos planos de aula e materiais didáticos propostos nos cursos que ministram? Quão familiarizados estão os professores em formação que atuam no contexto específico do IsF com as práticas de letramento acadêmico? Esses questionamentos, por sua vez, têm sido balizados pela necessidade de desenvolver um trabalho com os professores que venha questionar o ensino da escrita como mero conjunto de técnicas a ser apropriado pelo aprendiz em favor de uma visão enunciativo-discursiva e dialógica de linguagem, a qual compreende a palavra como "sempre carregada de um conteúdo ou de um sentido ideológico ou vivencial" (BAKHTIN/VOLOCHINOV, 2002 [1929], p. 95, grifos do autor).

Ademais, nosso trabalho tem sido orientado por perspectivas críticas de ensino-aprendizagem de línguas para fins acadêmicos, que, refutando concepções meramente pragmáticas, instrumentalistas ou utilitaristas (PENNYCOOK, 1994), trazem para o cerne de suas discussões as questões identitárias, as relações de poder, os conflitos constitutivos das práticas discursivas e as condições sóciopolíticas e econômicas que modelam as agendas educacionais (MORGAN, 2009).

Na esteira dessa visão, Canagarajah (2002) discute como uma perspectiva crítica de linguagem redimensiona a noção de escrita acadêmica. O autor aponta que, a partir de tal perspectiva, abandona-se uma visão autônoma, individualista, cognitiva, formal e espacial de escrita em prol de uma concepção de escrita situada, social, material, ideológica e histórica. Ele argumenta que essas diferenças podem ser resumidas na mudança de escrita como um objeto para o de escrita como uma atividade. Em suas palavras, "[...] é em percebendo a escrita como atividade situada, mediada, social dinâmica que o trabalho de prática crítica se inicia ${ }^{3 "}$

${ }^{3}$ Nossa tradução para "It is in perceiving writing as a situated, mediated, dynamic social activity that the work of critical practice begins". 
(CANAGARAJAH, 2002, p. 6). Dessa forma, passa-se a contemplar como, por exemplo, as questões identitárias dos escritores incidem na constituição do texto ou como este é moldado por suas condições de produção e recepção.

Ao fazer coro com tais perspectivas, intentamos interpelar os professores em formação a considerarem a dimensão heterogênea, fluida e situada da linguagem, pois entendemos ser esse um caminho possível para o desenvolvimento de propostas de ensinoaprendizagem de escrita acadêmica capazes de incidir significativamente na formação docente.

Em trabalho anterior (BRITO; SILVEIRA, 2018), discutimos a relação entre ensino e autoria, mais especificamente no que diz respeito à escrita de material didático pelos professores no âmbito do IsF. Esta, ao demandar do professor que se coloque na posição de autor, o interpela a tomar decisões acerca, por exemplo, da temática das unidades a serem trabalhadas; dos tipos de atividades e sua forma de sequenciação e organização; da própria configuração visual do material, dentre outras. Dessa forma, a escrita do material didático pode permitir ao sujeito implicar-se com o saber, contribuindo, assim, para sua formação profissional.

Dando continuidade às reflexões que temos empreendido sobre a relação sujeito-escrita, no programa, interessa-nos, no escopo desse trabalho, delinear algumas representações discursivas que se deixam capturar nos dizeres desses professores, ao enunciarem sobre a escrita acadêmica e seu ensino. Assim, na próxima seção, passamos à explicitação das condições de produção de seus dizeres, bem como à descrição e análise das representações.

\section{REPRESENTAÇÕES DISCURSIVAS SOBRE A/PELA ESCRITA ACADÊMICA}

Como parte das atividades pedagógicas voltadas para a formação dos professores no contexto do IsF, propusemos, ao grupo, quatro tarefas, no $\mathrm{Moodle}^{4}$, focadas no ensino-aprendizagem da escrita para fins acadêmicos. O objetivo era permitir que eles refletissem sobre a forma como significam sua relação com a escrita acadêmica nas línguas materna e estrangeira, no lugar de licenciandos em Letras (tendo, pois, que se apropriar de gêneros acadêmicos durante a formação) e de professores de LI (tendo, pois, que ensinar gêneros acadêmicos aos seus alunos).

A primeira tarefa - Thinking about writing - solicitava que os professores escrevessem um texto, no fórum de discussão, respondendo aos seguintes questionamentos: a) você gosta de escrever textos acadêmicos? Com que frequência você escreve textos em português? E em inglês?; b) Como você se sente ao escrever textos acadêmicos em inglês ou português?; c) Você já ministrou algum curso de escrita no IsF? Como foi? Fale sobre sua experiência no que se refere aos objetivos do curso, ao desenvolvimento de material, as dificuldades que você encontrou e como você as superou etc. Na segunda tarefa proposta para o tema em questão, os alunos deveriam ler um texto sobre crenças acerca da escrita e gravar um pequeno vídeo comentando uma das crenças mencionadas pelo autor. Na terceira tarefa, solicitamos que os professores preparassem um plano de aula para o curso de "Produção Escrita: Parágrafos" (nível A2 no QCE), com base em um artigo intitulado Does 'phone separation anxiety' really exist? Finalmente, na última tarefa, os professores deveriam escrever um texto de forma a refletir sobre suas percepções acerca da discussão sobre o processo de escrita, levando em consideração: a) o que aprenderam; b) a interação entre os pares; c) a relevância da discussão para a prática pedagógica, entre outros.

Para o escopo desse trabalho, restringir-nos-emos à análise das postagens feitas na primeira tarefa proposta na discussão sobre academic writing, na qual os professores se posicionaram acerca de suas experiências com a escrita acadêmica como aprendizes e professores. Para a análise do corpus, adotamos uma metodologia de base qualitativa, em que descrevemos, analisamos e interpretamos as regularidades enunciativas que emergem dos dizeres dos sujeitos. Vale salientar que compreendemos regularidades, segundo Santos (2004), para quem estas se constituem como evidências significativas que "[...] aparecem como elementos de recorrência, de idiossincrasia enunciativa, ou ainda, de efeito provocado pela natureza de organização dos sentidos" (SANTOS, 2004, p. 114). Essas regularidades são aqui apresentadas por meio de sequências discursivas que, por sua vez,

\footnotetext{
${ }^{4} \mathrm{O}$ grupo de professores bolsistas do NucLi-IsF em questão se reunia semanalmente para encontros presenciais de formação pedagógica, nos quais eram discutidos textos teóricos, elaborados planos de aulas e material didático etc. O Moodle funcionava como ferramenta de apoio a esses encontros.
} 
"representam conjuntos de enunciados recortados do escopo da manifestação em estudo" (SANTOS, 2004, p. 114). Em outras palavras, trata-se de investigar como o interdiscurso (enquanto 'já-dito', fio vertical do dizer) irrompe na materialidade linguística (intradiscurso), acenando para as memórias evocadas pelos sujeitos ao enunciarem sobre o tema em questão.

Dez professores responderam à tarefa, sendo seus níveis de proficiência linguística entre B2 e C2. Havia no grupo professores mais antigos (há quase 2 anos do IsF) e outros recém chegados no programa. Além disso, o grupo se constituía de professores que cursavam diferentes períodos do curso de Letras, sendo que um estava na pós-graduação.

Organizamos nosso gesto de interpretação do corpus em três eixos conforme as perguntas feitas na tarefa em questão e destacamos um enunciado que sintetizasse as regularidades enunciativas dos dizeres. Tais enunciados são atravessados por discursos ${ }^{5}$ que, por sua vez, mobilizam memórias sócio-ideologicamente constituídas e que se reatualizam no processo enunciativo.

Vejamos a primeira representação.

1) A representação da escrita acadêmica em relação à frequência com que se escreve: "quase não escrevo textos acadêmicos em LI"

A frequência com que os professores relatam a prática da escrita acadêmica é variável e colocada em relação com outras experiências (outras graduações cursadas, período em que estão no curso, relação com a pós), mas, de forma geral, vê-se que ela é representada como atividade não muito comum, como se observa nas sequências abaixo:

SD1: I occasionally write academic texts, but I enjoy writing them - most of the time I write about a topic that I am interested in or that I am studying and it is related to English teaching ${ }^{6}$. (Mirtes)

SD2: I enjoy writing academic texts and even though I'm a grad student, surprisingly, I don't have to write as much academic texts as I had to during my undergrad course. And now that I'm no longer taking courses in English, all my academic texts are now written in Portuguese. (Irene)

SD3: Many times we end up writing texts based on our intuition and not because we know the genre and are proficient on it. It happens almost every time I write papers in Portuguese, in school I had a lack of formal education on how to write the most known genres the biggest focus was on essays and that was it. And in college not all professor take the time to explain to us exactly how we are supposed to write, especially those who propose assignments in Portuguese. The only exception are the discipline that focuses on writing and was only then that I had a sort of formal education on writing, all my previous knowledge was built independently based on content I found on internet. (Teresa)

SD4: All that I know about writing academic texts are a compilation of the knowledge that I had from my graduation course and 70\% cames from the writing courses that I taught at ISF. (Tânia)

SD5: I must confess that I do not like to write academic texts. This attitude that I have towards this specific genre might be a consequence of how little I was exposed to it, not only during my undergraduation course, but also in my life, as a whole /.../ Once in a while some professors ask us to write an analysis, essay or paper in English, which can be somehow difficult to execute, especially if we consider my English learning experience (João)

SD6: I really enjoy writing. That was one of the reasons I chose Journalism as my first graduation choice, but I must confess that academic writing is not what I like to write the most. Ironically, in my first graduation, I didn't have to write them as much as I should, but in Letras I feel like I am gaining more practice in it, in Portuguese (Daisy)

\footnotetext{
${ }^{5}$ Os professores foram identificados por nomes fictícios e autorizaram o uso de suas postagens para fins de pesquisa.

${ }^{6}$ As sequências foram transcritas tais como produzidas pelos professores.
} 
Ao se referirem à frequência com que escrevem textos acadêmicos em LI, os sujeitos se inscrevem no discurso da não familiaridade com a escrita acadêmica, produzindo um efeito de estranhamento em relação a ela. Esse estranhamento se deixa marcar, intradiscursivamente, pela presença de uma tensão enunciativa. Observamos, por exemplo, a tensão entre gostar de escrever textos acadêmicos, mas não ser solicitado a fazê-lo (SD1: most of the time I write about a topic that I am interested in); a tensão entre gostar de escrever e fazê-lo apenas como fruto de uma demanda institucional (SD2: even though I'm a grad student, surprisingly, I don't have to write as much academic texts); a tensão entre gostar de escrever, mas não da escrita acadêmica (SD6: I must confess that academic writing is not what I like to write the most.); e a tensão entre não gostar de escrever e ter que realizar tal atividade ainda que esporadicamente (SD5: I must confess that I do not like to write academic texts).

Essa tensão, por sua vez, acena para uma memória discursiva acerca da historicidade do processo de ensino-aprendizagem da escrita para esses sujeitos: em seus dizeres, vem à tona o apagamento desse processo durante a vida escolar (SD3: in school I had a lack of formal education on how to write; SD5: might be a consequence of how little I was exposed to it, not only during my undergraduation course, but also in my life), a vida acadêmica universitária (SD5: Once in a while some professors ask us to write an analysis, essay or paper in English) e parece se estender à pós-graduação (SD2: even though I'm a grad student, surprisingly, I don't have to write as much academic texts). Dessa forma, tais contextos são representados como não-lugares para a aprendizagem da escrita e esta parece ser fruto da intuição (SD3: we end up writing texts based on our intuition); do estudo autônomo (SD3: knowledge was built independently); ou da prática docente (SD4: 70\% cames from the writing courses that I taught at ISF). Isto é, consolida-se o sentido de que se aprende a escrever apesar dos contextos formais de ensino.

Teresa, ao afirmar que in college not all professor take the time to explain to us exactly how we are supposed to write (SD3), (d)enuncia aquilo que Street (2009) denominou de dimensões 'escondidas' da escrita (hidden features), para se referir a não explicitação dos critérios avaliativos da escrita acadêmica nos mais diversos contextos, como se a escrita consistisse em uma habilidade técnica, neutra e independente de sua instância de produção.

No caso de nosso corpus, percebe-se que a falta de frequência do ato de escrita ocorre tanto na língua materna como na estrangeira. Desse modo, os dizeres nos levam ao questionamento das práticas de linguagem que constituem a formação do professor de línguas: que gêneros acadêmicos têm sido priorizados nas licenciaturas? Ou que práticas de letramento são dadas aos licenciandos experienciarem para além de uma metalinguagem? Não intentamos com tais reflexões consolidar o discurso do déficit, segundo o qual a não correspondência entre a escrita dos alunos e as expectativas dos professores é vista "[...] como reflexo da incapacidade dos estudantes em escreverem" (FIAD ${ }^{7}, 2016$, p. 210). Pelo contrário, compreendemos que a inserção - ou inscrição - dos alunos nas práticas de letramento acadêmico se constitui como processo complexo e tenso-conflitivo que precisa ser pensada para além de visões tecnicistas.

Trata-se, assim, de indagações que precisam ser melhores investigadas no intuito de se repensar o papel da escrita como instância de formação docente. A não frequência de práticas de escrita acadêmica não pode, a nosso ver, ser resolvida com o simples acréscimo de atividades de escrita, mas com propostas que promovam ao aluno "[... a possibilidade de se dizer, mais do que dizer, de se expor, mais do que expor para que vivencie a experiência do estranhamento (unheimilichkeit), a construção de si, de uma identidade ilusória" (CORACINI, 2010, p. 46). Esse estranhamento, diferente do advindo da ausência de práticas de escrita, diz respeito à natureza opaca e heterogênea da linguagem, sendo, pois, constitutivo da tomada da palavra, a qual movimenta redes de sentidos, sempre equívocos e passíveis de se tornarem outros (estranho) por meio dos gestos de interpretação dos sujeitos (PÊCHEUX, 2002 [1983]).

2) A representação da escrita acadêmica em relação ao processo de escrita em si: "a escrita acadêmica demanda mais que as outras habilidades"

Ao enunciarem sobre o ato da escrita acadêmica, os professores a representam como habilidade exigente e desafiadora. Vejamos.

\footnotetext{
${ }^{7}$ Fiad (2016) discute como uma proposta de escrita de um diário acerca de atividades relacionadas a uma disciplina, cujo foco era a produção de um glossário de gêneros discursivos, propiciou a apropriação de novas práticas de letramento por estudantes recém entrados na universidade. O estudo de Fiad é interessante por apontar que escritas acadêmicas não legitimadas podem contribuir para a entrada dos alunos nos modos de dizer consagrados na academia.
} 
SD7: However, it is not a sea of roses: academics texts require concentration, and they are time-consuming and challenging. (Mirtes)

SD8: I always considered my linguistic knowledge for writing a little poor. I know I am getting better, but I still do not feel safe enough to write academically in English /... I hope I can say in the future that I have mastered the art of writing in English (Lauro).

SD9: When a professor asks for the assignment in English I instantly feel a mix of insecurity and fear which makes me feel unmotivated to do the task proposed. And the moment I finish it and hand to my professor it becomes a matter of preoccupation, mostly I do well, but I tend to project my knowledge on Portuguese academic writing to English. (Teresa)

SD10: I feel comfortable to write academic texts and I like it, although I have difficulties to write considering the proper grammar and punctuation, all these problems are getting overcame with the practice and my studies. (Tânia)

SD11: The processes of writing an academic text is time-consuming, it requires research, concentration and dedication /.../ (Daisy)

As escolhas lexicais (not a sea of roses; time-consuming, challenging) usadas para se referir à escrita inscrevem essa prática em um imaginário de dificuldade, sobretudo em relação às outras habilidades. A escrita acadêmica demandaria concentração, tempo, pesquisa, dedicação (SD11: text is time-consuming, it requires research, concentration and dedication) e conhecimento mais especializado da própria língua (SD8: my linguistic knowledge for writing a little poor e SD 10: I have difficulties to write considering the proper grammar and punctuation).

Os professores evocam o discurso da (im)possibilidade do domínio da escrita acadêmica, intensificando a tensão que se (des)vela no dizer em relação a essa prática. Mirtes, por exemplo, apesar de ter mencionado, na SD1, que gosta de escrever textos acadêmicos e que o faz para estudar (ou seja, sem a necessidade de uma demanda institucional), introduz, na SD7, pelo uso de uma conjunção adversativa (however), seu posicionamento em relação à escrita acadêmica: a de que ela é desafiadora, demanda tempo e concentração.

Lauro, na SD8, avalia seu conhecimento linguístico para a escrita como sendo pobre, atribuindo, dessa forma, a este o caráter de fixidez, como se tal conhecimento fosse estático e estivesse pronto para ser provavelmente acessado pelo sujeito. A escrita acadêmica em LI é representada por ele como algo ameaçador (I still do not feel safe enough to write academically in English), sendo o devir (I hope I can say in the future that I have mastered the art of writing in English) uma forma de resistência diante da falta que se percebe. Aliás, a escrita acadêmica parece ser elevada a um status de inalcançabilidade tal que é nomeada como 'arte'.

Teresa, por sua vez, na SD9, ressalta os sentimentos de insegurança e medo em relação não apenas ao ato de escrever (feel a mix of insecurity and fear), mas também à expectativa do retorno de seu trabalho pelo professor (the moment I finish it and hand to my professor it becomes a matter of preoccupation). Nesse sentido, vê-se que o interlocutor é representado como mero avaliador, para quem importaria mais o 'domínio’ de um conteúdo do que um processo de construção de sentidos na/pela linguagem escrita. Ademais, vale ressaltar a ilusão de completude - e controle - de Teresa ao mencionar o conhecimento na língua materna como algo que pudesse ser transposto - sem conflitos ou alterações - para a escrita em língua inglesa (I tend to project my knowledge on Portuguese academic writing to English).

A ilusão de completude/controle e a projeção no futuro do domínio da escrita também reverberam nos dizeres de Tânia, ao mencionar que está superando problemas de gramática e pontuação por meio da prática e dos estudos (SD10: all these problems are getting overcame with the practice and my studies). Não queremos com isso dizer que não haja possibilidade de aperfeiçoamento, antes nos interessa ressaltar que a tensão que marca a relação do sujeito com a escrita não advém de problemas técnicos ou 
meramente linguísticos, antes diz respeito à impossibilidade de se dissociar a tomada da palavra de suas condições de produção. Talvez seja essa a razão da escrita, ao mesmo tempo em que é percebida como comfortable, também ser vista como algo que apresenta obstáculos (although I have difficulties).

No caso, de nosso corpus, poderíamos citar a própria resistência dos professores, manifesta na queixa ou no adiamento para a realização da atividade no Moodle, como sintoma da tensão que constitui a tomada da palavra na/pela escrita acadêmica. Para além de justificativas de ordem prática (falta de tempo, esquecimento), cremos que haja a resistência - ainda que insconsciente - do sujeito em engajar-se no processo de inscrição que essa escrita demanda, uma vez que

[...] escrita significa, ao mesmo tempo, um movimento para fora (ex-scripta) - de si para o outro - e um movimento para dentro (in-scripta) - do outro para si, do outro em si - de modo que a escrita, ou melhor, a escrita implica na inscrição daquele que (ex)põe suas ideias, seus sentimentos, seus afetos e desafetos, ao mesmo tempo em que o sujeito se vê envolvido (marcado) pelo que escreve. (CORACINI, 2010, p. 24)

Desse modo, mais do que tempo, concentração, pesquisa e dedicação, a demanda da escrita refere-se a uma "demanda de si", de tornar-se outro na relação que se (des)tece desde sempre com o(s) outro(s) nos processos de significação. Enfim, trata-se da demanda de dizer o dito de forma singular, já que "as palavras do outro, introduzidas na nossa fala, são revestidas inevitavelmente de algo novo, da nossa compreensão e da nossa avaliação, isto é, tornam-se bivocais” (BAKHTIN, 2002, p. 195).

\section{3) A representação da escrita acadêmica em relação ao seu processo de ensino: "a aula de escrita (acadêmica) é enfadonha"}

Ao enunciarem sobre o ensino da escrita acadêmica em LI, no âmbito do IsF, os sujeitos parecem mobilizar a memória discursiva acerca do ensino de línguas estrangeiras, no que diz respeito ao seu aspecto lúdico e interativo. Dessa forma, os professores se inscrevem no discurso da (im)possibilidade de se ensinar a escrita acadêmica e representam a aula como prática que desafia o professor a buscar meios de contornar seu caráter enfadonho. Vejamos.

SD12: I think one of the difficulties regarding writing courses is that students find it boring. I notice that most learners believe they only know ${ }^{8}$ English when they speak, and maybe that is why they prefer speaking courses instead of writing. (Mirtes)

SD13: I had plenty opportunities to teach Writing at ISF and those weren't my favorites experiences. Most students enrolled on writing courses due to the time or day of the week and weren't truly interested in improving their writing skills. The lack of interest in writing activities were my main challenge to overcome during those classes, because it made the classes dull sometimes. (Irene)

SD14: /.../ I only offered TOEFL oriented writing courses. And I can tell you for sure that it was a challenge for me. Because I always felt insecure about my ability to write in English, I usually delivered not so good classes. / ... I read my students essays, I gave them feedback based on the rubrics and etc. But it never sounded natural for me. (Lauro)

SD15: One of the challenges of a writing course in my opinion is being creative in terms of activities and on how present content since students tend to find writing classes too boring. And so I always try to find different activities and ways to practice without getting boring and exhausting. (Teresa)

SD16: The initial process of teaching academic writing was very challenging because I had never taught such skill and I was scared and lost of what I could teach and how, but with the assistance of teachers that had already taught this course and assistance of the pedagogical coordinator I could develop a good course /.../ (Tânia)

${ }^{8}$ Italicização feita pela professora. 
SD17: In the beggining, it was very hard for me to understand how a writing class goes, the pace, the concerns I should have, in general, I wasn't quite sure what I was supposed to do. But with some help from [nome] and [nome] and after meeting Cris I found a direction, and I think both me and my students really benefitted from the way the course turned out. (Maria)

SD18: /.../ academic writing is the most difficult skill in the academic context when it comes to performing and teaching. This is a result of the lack of encouragement that we see in our educational system, and society as a whole/.../ a writing course is often heavier than other courses and it can be boring. / ... I always try to bring some games and activities to my classes, in order to stimulate my students to discuss topics and the writing skill itselfin a more dynamic way. (Joanne)

SD19: / .../ and I would face it as a challenge to teach an ISF course on Writing. (Daisy)

Para justificar a falta de interesse dos alunos nas aulas de escrita, Mirtes traz à baila o discurso muito consolidado de que saber inglês é saber falar a língua (BRITO; GUILHERME, 2014), como se vê na SD12: that is why they prefer speaking courses instead of writing. Tal desmotivação ressoa nas demais sequências (SD13: weren't truly interested in improving their writing skills; SD15: students tend to find writing classes too boring; SD17: writing course is often heavier than other courses and it can be boring), reforçando a imagem de que essa aula é um desafio ao professor (SD14: challenge for me.; SD16: The initial process of teaching academic writing was very challenging; SD18: most difficult skill; SD19: I would face it as a challenge to teach an ISF course on Writing).

Além do aspecto enfadonho das aulas, vem também à tona, nos dizeres, a falta de experiência para ensinar a escrita. Lauro, por exemplo, afirma que os cursos de escrita que ministrou never sounded natural for me (SD14), o que a nosso ver aponta para a não familiaridade com determinadas práticas de letramento acadêmico (Because I always felt insecure about my ability to write in English). Em outras palavras, ao atribuir ao ensino da escrita acadêmica o caráter de 'não natural', Lauro assume que as outras práticas o sejam, escamoteando, assim, o apagamento - histórico - do ensino da escrita (acadêmica ou não), o qual é comumente relegado a segundo plano ao longo da vida escolar. Isso reverbera nos dizeres de Tânia e Maria, ao afirmarem seu desconhecimento quanto ao que fazer nas aulas (SD16: I was scared and lost of what I could teach e SD17: I wasn't quite sure what I was supposed to do), isto é, o ensino da escrita parece se constituir no apagamento de uma memória discursiva (SD: it was very hard for me to understand how a writing class goes).

Ao representarem o ensino da escrita acadêmica como aula enfadonha e manifestarem sua insegurança em conduzir uma aula de escrita, os professores atribuem aos alunos o julgamento de que a aula não seja motivadora. Todavia, como falar do outro é também falar de si, entendemos que é de seu lugar como aprendizes que enunciam.

Nos dizeres dos professores, a 'solução' para o caráter enfadonho da aula seria fazer uso de atividades lúdicas (SD15: being creative in terms of activities; SD18: I always try to bring some games and activities to my classes), que, de alguma forma, trouxessem mais dinamicidade à aula. Todavia, o que parece escapar a eles é a necessidade de se colocarem como interlocutores dos textos produzidos pelos alunos, isto é, de lançar para eles um gesto de escuta tal que seja capaz de afetar a forma como escrevem, interpelando-os a tomarem uma posição na/pela escrita.

Nesse sentido, entendemos que as considerações de Bertoldo (2017) acerca do papel do professor formador no processo de entrada dos licenciandos na ordem do discurso acadêmico também são pertinentes aqui. Para o autor,

[...] a relação com o professor formador pode ser fundamental para algum êxito que se pretenda nesse processo, uma vez que ele pode mediar a tensão produzida entre os modos de dizer da aluna e aqueles que o discurso acadêmico impõe, possibilitando que as dificuldades/impasses vividos pelos alunos, característicos da entrada na ordem do discurso acadêmico, possam ter um destino produtivo. (BERTOLDO, 2017, p. 118). 
Assim, se há, para o professor, um desafio na aula de escrita acadêmica, diríamos que seria justamente a de se colocar como mediador, trazendo vozes outras e acenando os modos possíveis de entrada no discurso acadêmico-científico. Trata-se de um desafio, pois essa mediação demanda que o professor já tenha feito essa entrada e se apropriado, de alguma forma, dos modos de dizer (tanto em língua materna quanto estrangeira), ainda que para subvertê-los.

Finalmente, há de se ressaltar que, diante do desafio de ensinar a escrita, Tânia e Maria também destacam a importância da aprendizagem com os pares e da orientação pedagógica que recebem no IsF (SD16: with the assistance of teachers that had already taught this course and assistance of the pedagogical coordinator I could develop a good course; SD17: with some help from [nome] and [nome] and after meeting [nome] I found a direction). Desse modo, podemos dizer que o programa tem se configurado como instância relevante para a formação de professores, oportunizando-lhes experienciar práticas outras de ensino-aprendizagem da língua estrangeira.

\section{CONSIDERAÇÕES FINAIS}

A partir da análise dos dizeres de professores em formação que atuaram no IsF, delineamos três representações sobre a escrita acadêmica e seu ensino, sintetizadas pelos seus respectivos enunciados: i) a escrita acadêmica é incomum - "quase não escrevo textos acadêmicos em LI"; ii) a escrita acadêmica é exigente - "a escrita acadêmica demanda mais que as outras habilidades"; e iii) a aula de escrita acadêmica é desmotivante - "a aula de escrita (acadêmica) é enfadonha”.

Tais representações são sustentadas, respectivamente, pelo que denominamos de discurso da não familiaridade com a escrita acadêmica, discurso da (im)possibilidade do domínio da escrita acadêmica e discurso da (im)possibilidade de se ensinar a escrita acadêmica. Separamos os discursos por questões de análises, mas sabemos que eles funcionam dialogicamente, atravessando as representações e mobilizando vozes em embate.

Nossas análises acenam a constituição de uma memória discursiva que (des)vela a tensa relação do sujeito, professor brasileiro de língua inglesa, com a escrita acadêmica, em língua materna ou inglesa. A falta de familiaridade com o ato da escrita acadêmica reforça a percepção de que a escrita e seu ensino são da ordem da (im)possibilidade. Defendemos, pois, a necessidade de se promoverem, nos cursos de formação de professores de línguas, experiências teórico-pedagógicas, em que os sujeitos possam aprender não apenas sobre a escrita e seu ensino, mas que possam se colocar no lugar de enunciadores na/pela língua (materna e estrangeira) escrita acadêmica. Ou seja, é preciso oportunizar a tomada significante da palavra de forma a permitir que o professor em formação sustente discursividades específicas à sua área de atuação profissional.

É preciso ainda problematizar discursos naturalizados que deslegitimam o falante brasileiro de língua inglesa, o qual parece ser afetado pelo imaginário de língua inglesa como língua inatingível. Se a oralidade é inalcançável por ser idealizada (pelo mito do nativo); a escrita acadêmica o parece ser por sua especificidade e especialização. Entendemos que um caminho para essa desconstrução se encontra justamente na prática da escrita como central nos processos de formação e de ensino-aprendizagem de línguas.

Ao ocupar o lugar de professor, a escrita passa de objeto de estudo para objeto de ensino, reposicionando discursivamente o sujeito na sua relação com o processo de escrever, o que pode contribuir para sua aprendizagem. Todavia, apesar de interpelar o professor em formação a estabelecer outra relação com a escrita (desconstruindo noções tecnicistas e totalizantes a respeito desta, por exemplo); não há garantias de que ele vá escrever, daí a necessidade de se considerarem práticas de linguagem, nos cursos de formação, que priorizem efetivamente o engajamento discursivo na/pela escrita, tanto em língua materna quanto estrangeira.

Pensar a escrita como pilar na formação nos leva a questionar não apenas aquilo que o professor diz ao mobilizar a linguagem para se posicionar, mas como o faz. Trata-se, assim de considerar como ele se representa na/pela escrita em língua materna e em uma língua outra e que modos de dizer lhe são possíveis em diferentes línguas. Em outras palavras, como seu objeto de estudo/ensino 
pode ser construído pela/na escrita acadêmica em diferentes línguas, haja vista que estas lhe permitem ocupar distintas posições discursivas, por meio de complexos movimentos de identificação.

\section{REFERÊNCIAS}

AUGUSTINI. C.; BERTOLDO, E. (org.). Incursões na escrita acadêmico-universitária: letramento, discurso, enunciação. Uberlândia: EDUFU, 2017.

BAKHTIN, M. (Voloschinov). Marxismo e filosofia da linguagem. 9. ed. São Paulo: Hucitec, 2002 [1929].

BAKHTIN, M. Para uma filosofia do ato responsável. Trad. Valdemir Miotello e Carlos Alberto Faraco. São Carlos: Pedro \& João Editores, 2010 [1920].

BAKHTIN, M. Problemas da poética de Dostoiévski. 3. ed. Rio de Janeiro: Forense Universitária, 2002.

BERTOLDO, E. O professor no processo de constituição do aluno pela escrita acadêmica. In: AUGUSTINI. C.; BERTOLDO, E. (org.). Incursões na escrita acadêmico-universitária: letramento, discurso, enunciação. Uberlândia: EDUFU, 2017. p. 107-120.

BRITO, C. C. P. Entretecendo vozes na (re)escrita de diários reflexivos de professores de línguas em formação inicial. SIGNUM: estudos da linguagem, Londrina, v. 15, n. 2, p. 65-83, dez. 2012.

BRITO, C. C. P.; SILVEIRA, P. H. Ensino e autoria: sobre a elaboração de material didático para um curso de produção oral no Programa IsF. Olhares e Trilhas, Uberlândia, v. 20, n. 3, p. 44-60, 2018.

BRITO, C. C. P.; GUILHERME, M. F. F. Memorial de aprendizagem e a formação do professor: vozes constitutivas da relação aprender/ensinar línguas estrangeiras. Revista Brasileira de Linguística Aplicada, Belo Horizonte, v. 14, n. 3, p. 511-532, 2014.

CANAGARAJAH, A. S. Critical academic writing and multilingual students. Michigan: The University of Michigan Press, 2002.

CORACINI, M. J. R. F. Discurso e escrit(ur)a: entre a necessidade e a (im)possibilidade de ensinar. In: ECKERT-HOFF, B. M.; CORACINI, M. J. R. F. (org.). Escrit(ur)a de si e alteridade no espaço papel-tela: alfabetização, formação de professores, línguas materna e estrangeira. Campinas, SP: Mercado de Letras, 2010. p. 17-50.

CRISTOVÃO, V. L. L.; BEATO-CAETANO, A. P. M. A formação de professores de línguas para fins específicos com base em gêneros textuais. DELTA, São Paulo, v. 32, n. 1, p. 45-74. 2016.

FAIRCHILD, T. A escrita escuta? Análise polifônica de relatórios de estágio. Raído, Dourados, v. 12, n. 27, p. 267-291, jan./jun. 2017.

FIAD, R. S. A escrita na universidade. Revista da Abralin, v. eletrônico, n. especial, p. 357-369, 2ª parte, 2011. Disponível em: https://revistas.ufpr.br/\%20abralin/article/viewFile/32436/20585. Acesso em: 7 mar.2019.

FIAD, R. S. Uma prática de letramento acadêmico sob análise. In: FIAD, R. S. (org.). Letramentos acadêmicos: contextos, práticas, percepções. São Carlos: Pedro \& João Editores, 2016. p. 201-222.

JUCHUM, M. A escrita na universidade: uma reflexão com base no que os alunos dizem em seus textos. Horizontes de Linguística Aplicada, Brasília, v. 13, n. 1, p. 107-129, 2014. 
MARINHO, M. A escrita nas práticas de letramento acadêmico. Trabalhos em Linguística Aplicada, Belo Horizonte, v. 10, n. 2 , p. 363-386, 2010.

MORGAN, B. Fostering transformative practitioners for critical EAP: possibilities and challenges. Journal of English for Academic Purposes, v. 8, p. 86-99, 2009.

OLIVEIRA, H. A. G; ARAÚJO, D. L. Representações sociais de escrita em curso de formação docente: objeto de ensino e objeto de inserção nas práticas letradas acadêmicas. SCRIPTA, Belo Horizonte, v. 21, n. 43, p. 277-298, 2017.

PÊCHEUX, M. Análise automática do discurso (AAD-69). In: GADET, F; HAK, T. (org.). Por uma análise automática do discurso: uma introdução à obra de Michel Pêcheux. Trad. Bethania S. Mariani et al. 3. ed., Campinas: Editora da Unicamp, 1997 [1969]. p. 61-105.

PÊCHEUX, M. Semântica e discurso: uma crítica à afirmação do óbvio. Trad. Eni Puccinelli Orlandi et al. Campinas: Editora da UNICAMP, 1997 [1975].

PÊCHEUX, M. (1983). O Discurso: Estrutura ou Acontecimento. 3. ed. Trad. Eni Puccinelli Orlandi. Campinas: Pontes. 2002 [1983].

RIOLFI, C. R. Lições da coragem: o inferno da escrita. In: RIOLFI, C. R.; BARZOTTO, V. H. (org.). O inferno da escrita: produção escrita e psicanálise. Campinas, SP: Mercado de Letras. 2011. p. 11-31.

SANTOS, J. B. C. Uma reflexão metodológica sobre análise de discursos. In: FERNANDES, C. A. e SANTOS, J. B. C. (org.). Análise do Discurso: unidade e dispersão. Uberlândia: EntreMeios, 2004. p. 109-118.

SARMENTO, S.; ABREU-E-LIMA, D.; MORAES FILHO, W. (org.). Do Inglês sem Fronteiras ao Idiomas sem Fronteiras. Belo Horizonte: Editora UFMG, 2016.

STREET, B. "Hidden" features of academic paper writing. Working Papers in Educational Linguistics, Philadelphia, v. 24, n. 1, p. 117, 2009.

\section{() (1) $\circledast \oplus$}

Recebido em 16/09/2019. Aceito em 22/12/2019. 